\title{
PRODUÇÃO DE INVERTASE POR FERMENTAÇÃO EM ESTADO SÓLIDO A PARTIR DE FARELO DE SOJA
}

\author{
Lexandra Novaki ${ }^{1}$ \\ Salah D. M. Hasan ${ }^{2}$ \\ Marina K. Kadowaki ${ }^{3}$ \\ Diandra Andrade ${ }^{4}$
}

\begin{abstract}
Resumo: A invertase é responsável pela hidrólise da sacarose na formação de açúcar invertido e é utilizada em indústrias alimentícias e farmacêuticas. Neste trabalho objetivou-se a produção da invertase por fermentação em estado sólido (FES) do farelo de soja por Aspergillus casiellus. Obteve-se atividade no extrato bruto de 1029,75 U.mg ${ }^{-1}$ após $72 \mathrm{~h}$ de fermentação. A recuperação por precipitação com sulfato de amônio e solventes foi menos eficiente que com o choque térmico. Análises de SDS-PAGE indicaram massa molecular da invertase em torno de $25,5 \mathrm{kDa}$ e a mesma manteve as condições ótimas em $\mathrm{pH} 4,0$ a $70^{\circ} \mathrm{C} \mathrm{com} 50 \%$ de atividade residual. Comprovou-se que o uso de resíduo agroindustrial para obtenção da invertase é uma alternativa importante visando o desenvolvimento de tecnologias limpas, convertendo o resíduo em um produto de maior valor agregado.
\end{abstract}

Palavras-chave: invertase, Aspergillus casiellus, fermentação em estado sólido.

\begin{abstract}
Invertase is a type of enzyme which catalyzes the sucrose hydrolysis at the inverted sugar production and is used by food and pharmaceutical industries. This paper aimed the production of invertase by solid state fermentation (SSF) of soybean bran by Aspergillus casiellus. It was obtained an enzyme activity of 1029.75 U.mg ${ }^{-1}$ in raw extract after $72 \mathrm{~h}$ of fermentation. The recovery by thermal shock was more efficient than precipitation with ammonium sulfate and solvent. SDS-PAGE analysis indicated a molecular mass of 25.5 $\mathrm{kDa}$ for the invertase obtained and the enzyme kept the optimum conditions at $\mathrm{pH} 4.0$ and $70^{\circ} \mathrm{C}$ with $50 \%$ residual activity. The utilization of the agricultural residue to obtain the invertase seems to be a good alternative for the development of clean technologies, converting the waste into a product of higher added value.
\end{abstract}

Keywords: invertase, soybean bran, Aspergillus casiellus, solid-state fermentation.

\footnotetext{
1 Departamento de Engenharia Química - Unioeste/Campus de Toledo/PR. E-mail: lexandra.n@hotmail.com

2 Departamento de Engenharia Química - Unioeste/Campus de Toledo/PR. E-mail: salahdmh@gmail.com

3 Centro de Ciências Biológicas - Unioeste/Campus de Cascavel/PR. E-mail: marinakk@unioeste.br

${ }^{4}$ Centro de Ciências Biológicas - Unioeste/Campus de Cascavel/PR. E-mail: andradediandra@hotmail.com
} 


\section{INTRODUÇÃO}

Em processos industriais a invertase ou $\beta$-frutofuranosidase é usada para obtenção do xarope de açúcar invertido. $\mathrm{O}$ açúcar invertido (xarope de glicose e frutose) é amplamente utilizado na indústria de confeitos, na panificação e produtos afins, na formulação de cremes para recheio e de geléias. $\mathrm{O}$ uso da invertase está principalmente relacionado à indústria alimentícia, tanto na fabricação do xarope de glicose e frutose (açúcar invertido) quanto com a formação dos frutooligossacarídeos (SAID \& PIETRO, 2004). A invertase é encontrada em leveduras, sobretudo na espécie Sacharomyces cerevisiae, invertebrados, vertebrados, algas verdes, bactérias, vegetais e fungos.

Um método de obtenção da invertase é através da fermentação em estado sólido (FES). $O$ interesse neste tipo de fermentação vem da sua simplicidade e proximidade das condições de crescimento natural de muitos micro-organismos, especialmente fungos, do consumo reduzido de energia e da não necessidade de utilização de equipamentos complexos e sistema de controle sofisticado. Devido à ausência de água livre, pequenos fermentadores são necessários e os processos de recuperação do produto são feitos com maior facilidade (DEL BIANCHI et al., 2001).

A geração de resíduos e subprodutos é inerente a qualquer setor produtivo. $\mathrm{O}$ aumento $\mathrm{da}$ conscientização ecológica, iniciado no final do século XX, deixou claro que o grande desafio da humanidade para as próximas décadas é equilibrar a produção de bens e serviços, crescimento econômico, igualdade social e sustentabilidade ambiental. Estes resíduos e subprodutos gerados pela agroindústria podem ser reaproveitados para obtenção de novos produtos.

Dentre os vários substratos citados na literatura, como farelo de trigo, torta de coco e babaçu, está a soja, que pode ser usada na forma de farelo ou grãos pré-tratados (triturados). Cereais, como o milho e o trigo e oleaginosas, como a soja, são produtos de composição química e bioquímica complexa que têm sido usados como matéria-prima nas mais diversas pesquisas que visam a exploração do potencial destes substratos, no campo da ciência e tecnologia de alimentos, pesquisa com biodiesel, na indústria farmacêutica e produtos naturais, etc. Sabe-se que a soja e o milho são fontes ricas para a obtenção de importantes metabólitos, incluindo enzimas hidrolíticas de diferentes tipos, como lipases, proteases e glicosidases, entre outras. Nas publicações encontradas sobre a produção de enzimas e outros metabólitos (PANDEY et al., 2000), por fermentação de cereais (na forma de farinha, farelo, etc.) verifica-se a utilização de soja do tipo convencional. Ao término do processo FES para produção de enzimas, os sólidos contêm células do fungo (micélio), além de substrato, enzimas e outros metabólitos. As enzimas não estão distribuídas de forma homogênea no meio fermentado e, neste caso, uma extração eficiente é determinante na produção comercial da enzima por FES. (SOCCOL \& VANDENBERGHE, 2003)

Atualmente, invertases proveni-entes de uma grande diversidade de micro-organismos vêm sendo estudadas, no entanto a produção da invertase produzida pelo fungo Aspergillus casiellus ainda não foi relatada. Assim, o objetivo deste trabalho foi a produção e a caracterização parcial da enzima invertase produzida pelo fungo Aspergillus casiellus por fermentação em estado sólido aproveitando o farelo de soja como substrato.

\section{MATERIAL E MÉTODOS}

\subsection{MICRO-ORGANISMO}

Foi utilizado o fungo Aspergillus casiellus do Laboratório de Bioquímica da UNIOESTE Cascavel. $\mathrm{O}$ fungo foi mantido em tubo inclinado contendo $5 \mathrm{~mL}$ de meio sólido de batata dextrose ágar (BDA). As culturas repicadas foram crescidas a $25^{\circ} \mathrm{C}$ por 13 dias, sendo após, estocadas em geladeira a $4^{\circ} \mathrm{C}$ por até 30 dias.

\subsection{PREPARO DO SUBSTRATO}

O substrato utilizado para a fermentação em estado sólido foi o resíduo de farelo de soja obtido de indústria local. A coleta foi efetuada uma única vez em quantidade suficiente para manter as características sempre iguais do material durante toda a pesquisa. $\mathrm{O}$ material foi estocado em freezer até o momento da sua utilização (GUIMARÃES et al., 2007).

\subsection{FERMENTAÇÃO EM ESTADO SÓLIDO (FES)}

Em frascos Erlenmeyer de $250 \mathrm{~mL}$, foram adicionados 2,0 g de farelo de soja, 2,0 $\mathrm{mL}$ de 
água corrente ou 2,0 $\mathrm{mL}$ de meio mineral Czapeck sem adição de extrato de levedura (COELHO, 2002), sendo após autoclavados. As culturas foram obtidas mediante inóculo de $1,0 \mathrm{~mL}$ de uma solução de esporos do micro-organismo Aspergillus casiellus, preparada com água corrente ou meio mineral Czapeck estéril. A FES transcorreu por períodos variáveis de 72 a $220 \mathrm{~h}$ em estufa à $25^{\circ} \mathrm{C}$ (processo em batelada). $\mathrm{O} \mathrm{pH}$ do meio foi ajustado para 7,0.

\subsection{EXTRAÇÃO E RECUPERAÇÃO DAS ENZIMAS}

Os extratos enzimáticos foram obtidos com adição de $50 \mathrm{~mL}$ de água destilada gelada aos meios sendo mantidos em incubadora shaker a $120 \mathrm{rpm}$ durante $60 \mathrm{~min}$ a $4^{\circ} \mathrm{C}$. Após, filtrou-se (papel Whatman $\mathrm{n}^{\circ} 1$ ) sendo os filtrados obtidos dialisados e mantidos em banho de gelo para determinação da atividade da invertase. A recuperação da invertase foi feita através da precipitação com os solventes orgânicos etanol e acetona. Para tanto foi adicionado o solvente gelado ao extrato bruto numa proporção de $2: 1$. O precipitado obtido foi secado e ressuspendido em água destilada. Para a precipitação com sulfato de amônio foram utilizadas as seguintes concentraçóes de sal: 35 , $45,55,65$ e $75 \%$. O precipitado foi ressuspendido em água deionizada, dialisado durante $12 \mathrm{~h}$ com trocas periódicas de água (NGUYEN et al., 2005).

\subsection{INFLUÊNCIA DOS PARÂMETROS PH E TEMPERATURA NA ATIVIDADE ENZIMÁTICA}

A temperatura ótima da invertase foi estimada incubando $1,0 \mathrm{~mL}$ do substrato sacarose 1,0 M, em tampão acetato de sódio $50 \mathrm{mM} \mathrm{pH}$ 4,0, com 1,0 mL do extrato enzimático diluído. A reação foi conduzida em diferentes ensaios enzimáticos, onde, em cada um deles, a temperatura foi ajustada $\left(40\right.$ a $\left.90^{\circ} \mathrm{C}\right)$. Para a avaliação da influência do $\mathrm{pH}$ na atividade invertásica, o substrato (sacarose 1,0 M) foi dissolvido em tampão McIlvaine $50 \mathrm{mM}$, com uma variação de $\mathrm{pH}$ de 2,2 a 8,0 (TANG et al., 1996).

\subsection{EFEITO DE SOLVENTES ORGÂNICOS, ÍONS, AGENTES REDUTORES E}

DETERGENTE SOBRE A ATIVIDADE DA INVERTASE

O efeito de alguns íons metálicos, solventes orgânicos e agentes redutores sobre a atividade da invertase foi avaliado pela incubação da enzima com sacarose 1,0 M diluída em tampão acetato de sódio $0,05 \mathrm{M}$ pH 4,0. Foram acrescentados à reação os seguintes solventes orgânicos: etanol, acetona e o agente redutor: $\beta$-mercaptoetanol; o detergente SDS, alguns íons $\left(\mathrm{Cu}^{+}, \mathrm{K}^{+}, \mathrm{Hg}^{+}, \mathrm{Na}^{+}\right.$, $\left.\mathrm{NH}_{4}^{+}, \mathrm{Sn}^{2+}, \mathrm{Ba}^{2+}, \mathrm{Cu}^{2+}, \mathrm{Al}^{3+}, \mathrm{Zn}^{2+}, \mathrm{Mg}^{2+}\right)$ em forma de solução, além de DTT, DMSO, Tween 80 , Triton x100, EDTA e cisteína, nas concentraçóes de 1 e 5 mM (ou 1 e 5\%) (NGUYEN et al., 2005).

\subsection{DETERMINAÇÃO DA ESPECIFICIDADE AO SUBSTRATO}

A especificidade da invertase ao substrato foi determinada por incubação da mistura de reação contendo $0,5 \mathrm{~mL}$ da enzima e $0,5 \mathrm{~mL}$ de substrato dissolvido em tampão acetato de sódio $0,05 \mathrm{M} \mathrm{pH} \mathrm{4,0,} \mathrm{à} \mathrm{temperatura} \mathrm{de} 60^{\circ} \mathrm{C}$. Foram usados os seguintes substratos: sacarose $1,0 \mathrm{M}$, amido $1 \%$, inulina $1 \%$, xilano $1 \%$, pectina $1 \%$ e trealose $20 \mathrm{mg} / \mathrm{mL}$. Foram retiradas alíquotas após 10, 20 e 30 minutos de reação, e adicionadas em DNS para determinação da atividade invertásica (HASHIZUME et al., 2003).

\subsection{MÉTODOS ANALÍTICOS}

As proteínas solúveis foram quantificadas através do método de Bradford (1976), utilizando BSA como padrão. A determinação da atividade enzimática foi realizada através da reação de ácido 3,5dinitrossalicílico (DNS) (MILLER, 1959) para açúcares redutores citada por Peralta (2003). A unidade de atividade da invertase foi definida como sendo a quantidade de micromols de açúcares redutores liberados por 1,0 mL de enzima em $1 \mathrm{~min}$, nas condições de ensaio $\left(\mathrm{U} \cdot \mathrm{mL}^{-1}\right)$. Atividade total (U total) $=\mathrm{U} / \mathrm{mL} \mathrm{x}$ volume do filtrado. Atividade específica $=(\mathrm{U}$ total $/$ miligrama proteína total $)$. A massa molecular da invertase foi estimada por SDS-PAGE, método descrito por Laemmli (1970). A coloração dos géis foi realizada segundo o método descrito por Blum et al. (1988). A eletroforese não-desnaturante foi realizada em géis de poliacrilamida conforme metodologia de Davis (1964) para proteínas ácidas. 


\section{RESULTADOS E DISCUSSÃO}

\subsection{OBTENÇÃO DE INVERTASE DE ASPERGILLUS CASIELLUS}

Foi observado que o farelo de soja, sem adição de nutrientes, resultou em atividade enzimática maior do que quando houve adição de nutrientes (Figura 1).

Experimentos foram realizados para estabelecer o melhor meio de cultivo para a produção de atividade invertásica, sendo avaliadas as fontes de carbono de soja (soja bruta granulada e farelo de soja) com água corrente (sem adição de meio mineral) e também, apenas na presença de meio mineral Czapeck sem adição de extrato de levedura. Nesta etapa foi verificado o melhor tempo de cultivo para a produção da invertase, avaliando a atividade da enzima. Na figura 1 pode ser observada atividade específica máxima após 72 horas de fermentação (1029,75 U.mg $\left.{ }^{-1}\right)$, utilizando como substrato o farelo de soja na presença de água corrente, sem adição de nutrientes. Portanto, essas condições foram utilizados para a produção de invertase a $25^{\circ} \mathrm{C}$ num processo em batelada. O tempo de 72 horas de fermentação também foi observado por Ashokkumar et al. (2001), no cultivo com Aspergillus niger utilizando bagaço de cana-de-açúcar em condições de fermentação em estado sólido a $30^{\circ} \mathrm{C}$, e a produção de invertase foi aumentada em quase 5 vezes quando desenvolvida em condições de fermentação sólida $\left(81,8\right.$ U.L $\left.L^{-1} \cdot h^{-1}\right)$ quando comparada à submersa (18,3 U.L $\left.{ }^{-1} h^{-1}\right)$. Já Bhatti et al. (2006) relataram uma maior produção de invertase após incubação de 96 horas utilizando o melaço como fonte de carbono pelo Fusarium solani, obtendo uma atividade invertásica máxima de 9,90 U.mL $\mathrm{mL}^{-1}$.

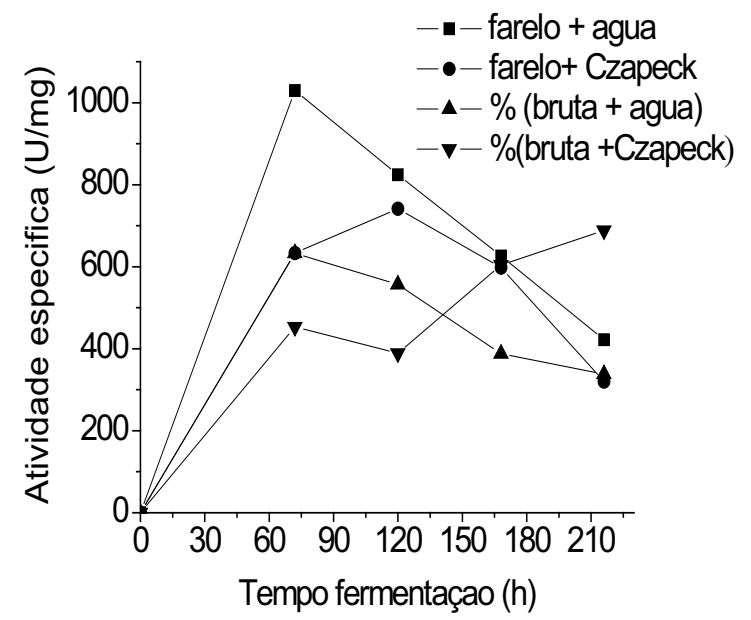

Figura 1 - Perfis de invertase de $A$. casiellus cultivado em farelo de soja e soja bruta (em meio mineral Czapeck ou água corrente), em processo FES em batelada.

\subsection{RECUPERAÇÃO DA ENZIMA MEDIAN- TE PRECIPITAÇÃO COM SOLVENTES OR- GÂNICOS E SULFATO DE AMÔNIO}

Na tabela 1 estão apresentados os resultados obtidos para as diferentes saturaçôes de sulfato de amônio para a recuperação da invertase por precipitação. Foi verificado que a etapa com saturação de $55 \%$ de $\left(\mathrm{NH}_{4}\right)_{2} \mathrm{SO}_{4}$, a enzima teve uma atividade de específica de 481,06 U/mg, apresentando $80,38 \%$ de recuperação, o que equivale a um fator de recuperação de 1,40 . A saturação com sulfato de amônio mostrou eficiência na precipitação da invertase numa faixa de 35 a 65\% de saturação, com aumento da atividade específica, mas acima de $75 \%$ de saturação foi observada a diminuição da atividade enzimática.

Tabela 1 - Perfis das frações obtidas na precipitação com sulfato de amônio - $\left(\mathrm{NH}_{4}\right)_{2} \mathrm{SO}_{4}$

\begin{tabular}{cccccc}
\hline \multirow{2}{*}{$\begin{array}{c}\text { Sulfato de amônio } \\
(\%)\end{array}$} & $\begin{array}{c}\text { Atividade da invertase } \\
\left(\mathrm{U} \cdot \mathrm{mL}^{-1}\right)\end{array}$ & $\begin{array}{c}\text { Proteína } \\
\left(\mathrm{mg}^{-} \mathrm{mL}^{-1}\right)\end{array}$ & $\begin{array}{c}\text { Atividade específica } \\
\left(\mathrm{U}^{-} \mathrm{mg}^{-1}\right)\end{array}$ & \multicolumn{2}{c}{ Recuperação } \\
\cline { 5 - 6 } & 377,06 & 1,09 & 342,93 & $\%$ & Vezes \\
\hline 0 & 259,00 & 0,62 & 417,74 & 68,00 & 1,00 \\
35 & 257,03 & 0,62 & 414,56 & 68,16 & 1,22 \\
45 & 303,07 & 0,63 & 481,06 & 80,38 & 1,40 \\
55 & 252,68 & 0,63 & 401,00 & 67,01 & 1,17 \\
65 & 202,95 & 0,61 & 332,70 & 53,82 & 0,97 \\
75 & 192,17 & 0,57 & 337,14 & 50,96 & 0,98 \\
85 & & & & &
\end{tabular}


Os resultados obtidos $(80,38 \%$ e $50,96 \%$ de recuperação usando, respectivamente, 55 e $85 \%$ de $\left.\left(\mathrm{NH}_{4}\right)_{2} \mathrm{SO}_{4}\right)$ foram inferiores ao obtido por Nguyen et al. (2005), que obtiveram aproximada-mente $90 \%$ de aumento na atividade específica da invertase de Aspergillus niger IMI303386 usando saturação de $80 \%$ de $\left(\mathrm{NH}_{4}\right)_{2} \mathrm{SO}_{4}$. Resultados com precipitações eficientes usando $85 \%$ de $\left(\mathrm{NH}_{4}\right)_{2} \mathrm{SO}_{4}$ e aumento de mais de 100 vezes na atividade específica para a invertase purificada foram descritos por Moreno et al. (1990), para a invertase obtida de Schizosaccharomyces pombe, mostrando uma porcentagem de recuperação da enzima muito superior ao encontrado para a invertase de $A$. casiellus desta pesquisa.

Precipitações com etanol e acetona também foram realizadas usando uma proporção de 2:1 (solvente:extrato bruto). Os resultados obtidos são relatados na tabela 2 .

Tabela 2 - Precipitação da invertase com solventes orgânicos

\begin{tabular}{cccccc}
\hline \multirow{2}{*}{ Solvente } & $\begin{array}{c}\text { Atividade da invertase } \\
\left(\mathrm{U} \cdot \mathrm{mL}^{-1}\right)\end{array}$ & $\begin{array}{c}\text { Proteína } \\
\left(\mathrm{mg} \cdot \mathrm{mL}^{-1}\right)\end{array}$ & $\begin{array}{c}\text { Atividade específica } \\
\left(\mathrm{U}_{\mathrm{m}} \mathrm{mg}^{-1}\right)\end{array}$ & \multicolumn{2}{c}{ Recuperação } \\
\cline { 5 - 6 } Extrato bruto & 381,09 & 1,15 & 331,38 & 1,00 & 100,00 \\
Etanol & 251,60 & 0,55 & 457,45 & 1,38 & 66,02 \\
Acetona & 297,04 & 0,48 & 618,83 & 1,87 & 77,94 \\
\hline
\end{tabular}

Quando comparadas ao extrato bruto, que apresentou atividade específica de 331,38 U/mg, durante as precipitações com os solventes etanol e acetona foram obtidos fatores de purificação de 1,38 vezes $(66,02 \%)$ para o etanol e 1,87 vezes $(77,94 \%)$ para a acetona, sendo as atividades específicas de 457,45 U.mg ${ }^{-1}$ e 618,83 U.mg ${ }^{-1}$, respectivamente.

Porém, tanto para a enzima recuperada através das precipitações com sulfato de amônio quan- to para os solventes utilizados, foi observado que durante o tempo de estocagem em freezer houve perda de atividade em torno de $30 \%$ a $40 \%$.

Além da recuperação da enzima invertase por precipitações com sulfato de amônio, etanol e acetona a recuperação também foi avaliada através da aplicação de um choque térmico em banhomaria a $60^{\circ} \mathrm{C}$, onde foi possível verificar os resultados expressos na Tabela 3.

Tabela 3 - Recuperação da invertase do extrato bruto pela utilização de choque-térmico

\begin{tabular}{cccccc}
\hline \multirow{2}{*}{ Etapa } & $\begin{array}{c}\text { Ativ. da invertase } \\
\left(\mathrm{U} \cdot \mathrm{mL}^{-1}\right)\end{array}$ & $\begin{array}{c}\text { Proteína } \\
\left(\mathrm{mg} \cdot \mathrm{mL}^{-1}\right)\end{array}$ & $\begin{array}{c}\text { Atividade } \\
\text { específica }\left(\mathrm{U}_{\mathrm{m}} \mathrm{mg}^{-1}\right)\end{array}$ & \multicolumn{2}{c}{ Recuperação } \\
\cline { 5 - 6 } & 215,91 & 1,155 & 186,93 & 1,00 & $(\%)$ \\
\hline Sem choque- térmico & $215)$ & 2681,48 & 14,34 & 109,00 \\
Com choque- térmico & 235,97 & 0,088 & 29 \\
\hline
\end{tabular}

A utilização do choque térmico resultou em um fator de recuperação da invertase de 14,34 vezes $(109,29 \%)$, sendo que este valor foi muito superior às recuperações quando utilizadas de outras formas de recuperação como precipitação com sulfato de amônio (máximo de 80,38\%), etanol $(66,02 \%)$ e acetona $(77,94 \%)$. A invertase obtida pela fermentação da soja usando o fungo filamentoso Aspergillus casiellus, apresenta-se como uma enzima termoresistente, acredita-se então, que durante o processo do choque-térmico outras proteínas residuais da soja não termoresistentes sejam desnaturadas e precipitadas durante a centrifugação, deixando de interferir na ação da enzima invertase, e assim, resultando em um aumento da atividade específica da mesma.

A recuperação da enzima através do choque térmico mostrou-se como uma alternativa 
eficaz para processos de purificação. Com isso, a recuperação da invertase obtida de Aspergillus casiellus pela fermentação em estado sólido do farelo de soja, foi realizada através de choque térmico, sendo a enzima recuperada estocada em freezer para posterior purificação em coluna cromatográfica.

A enzima purificada mostrou homogeneidade eletroforética em gel SDS PAGE 12\% (Figura 2), exibindo massa molecular aparente de 25,5 $\mathrm{kDa}$. Estes dados foram obtidos através de PAGE e SDS-PAGE. Através do PAGE, pode-se dizer que a invertase é um tetrâmero que se aproxima a fosforilase $b$.

Este resultado mostra massa molecular abaixo do que frequentemente é encontrado na literatura, como a invertase obtida da pêra japonesa por Hashizume et al. (2003), que por SDSPAGE apresentou massa molecular de 38 kDa. Já a invertase de $A$. niger purificada por L'Hocine et al. (2000) exibiu massa molecular em uma faixa maior, de 71 a $111 \mathrm{kDa}$ por SDS-PAGE, $79 \mathrm{kDa}$ de Aspergillus ochraceus (Guimarães et al., 2007), $65 \mathrm{kDa}$ de Fusarium solani (Bhatti et al., 2006).

A invertase obtida de cana de açúcar por Hussain et al. (2008) foi a qual mais se aproximou com a invertase do $A$. casiellus, apresentando massa molecular de $28 \mathrm{kDa}$ por SDS-Page.

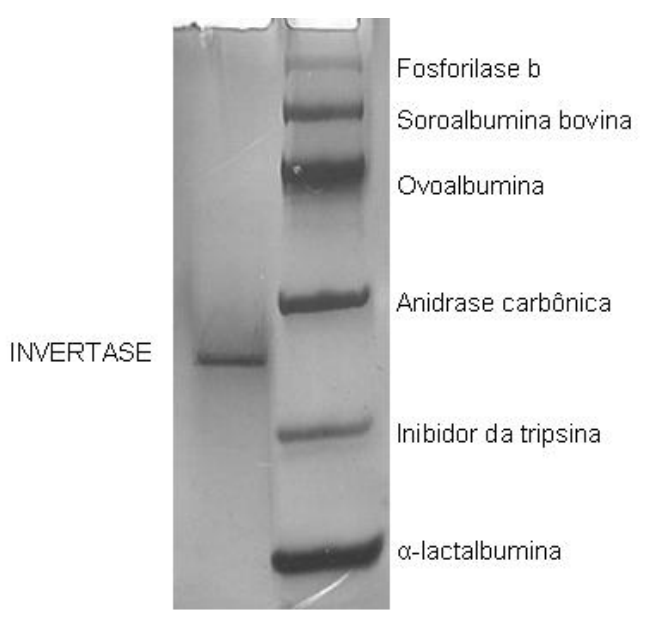

Figura 2 - Eletroforese em gel de poliacrilamida $12 \%$ da invertase do A.casiellus. Massa molecular dos marcadores: Fosforilase b $(97 \mathrm{kDa})$, Albumina $(66 \mathrm{kDa})$, Ovoalbumina $(45 \mathrm{kDa})$, Anidrase carbônica $(30 \mathrm{kDa})$, Inibidor da tripsina $(20,1 \mathrm{kDa}), \alpha$-lactalbumina $(14,4 \mathrm{kDa})$

\subsection{ANÁLISE DOS PARÂMETROS PH E TEMPERATURA NA ATIVIDADE ENZIMÁTICA}

A invertase purificada de $A$. casiellus apresentou atividade máxima a $70^{\circ} \mathrm{C}$ e reteve $50 \%$ de sua atividade residual nas temperaturas de $60 \mathrm{e}$ $65^{\circ} \mathrm{C}$ e aproximadamente $70 \%$ a $75^{\circ} \mathrm{C}$, como se observa na figura 3. Nas temperaturas inferiores a $60^{\circ} \mathrm{C}$ a invertase não atingiu $50 \%$ da sua atividade máxima. Este resultado mostra uma temperatura superior ao encontrado por Tang et al. (1996) onde a temperatura ótima para a invertase foi de $45^{\circ} \mathrm{C}$. Quanto à temperatura ótima, esta enzima mostrou-se mais eficiente do que as encontradas em outras espécies de Aspergillus, como por exemplo, a invertase de Aspergillus niger AS0023 apresentou uma temperatura ótima de $55^{\circ} \mathrm{C}$ e estabilidade a temperaturas de no máximo $65^{\circ} \mathrm{C}$ (L'HOCINE et al., 2000); e a produzida por $A$. ochraceus que apresentou temperatura ótima de $60^{\circ} \mathrm{C}$ e meia vida de $60 \mathrm{~min}$ a esta temperatura (GUIMARÃES et al., 2007).

Invertases de grau industrial - BIOINVERT $^{R}$ da QUEST INTERNA-TIONAL e INVERTIN $^{R}$ da MERCK - e analítico - das marcas FLUKA $^{\mathrm{R}}$ e SIGMA ${ }^{\mathrm{R}}$ - também apresentaram padrōes inferiores de temperatura ótima -55 , 60,55 e $55^{\circ} \mathrm{C}$ respectivamente - e de estabilidade a temperatura $-30-50^{\circ} \mathrm{C}$ para as primeiras e $30-55^{\circ} \mathrm{C}$ para as segundas (SAID \& PIETRO, 2004).

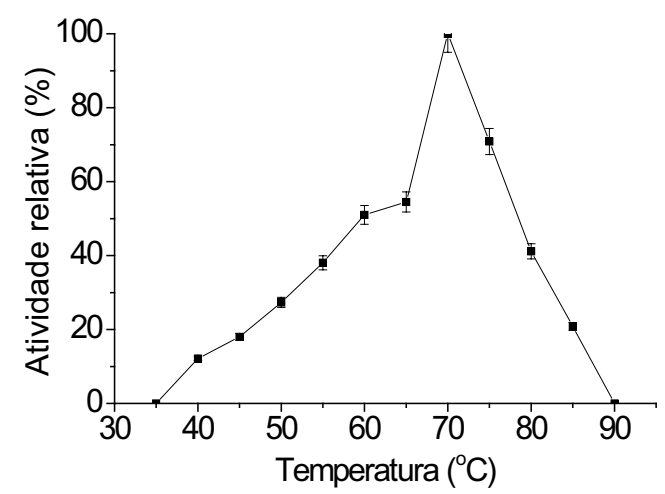

Figura 3 - Influência da temperatura sobre a atividade relativa da invertase.

Quanto ao efeito do $\mathrm{pH}$ no qual a enzima pura do Aspergillus casiellus apresentou atividade máxima ao $\mathrm{pH}$ foi 4,0 (Figura 4). Este $\mathrm{pH}$ ótimo ácido está próximo ao encontrado para 
as invertases da levedura Rhodotorula glutinis (RUBIO, RUNCO \& NAVARRO, 2002) e dos fungos Aspergillus niger AS0023 (L'HOCINE et al., 2000) e Aspergillus ochraceus (GUIMARÃES et al., 2007), bem como para as enzimas industriais BIOINVERT $^{\mathrm{R}}$ da QUEST INTERNA-TIONAL e INVERTIN ${ }^{\mathrm{R}}$ da MERCK $^{\mathrm{R}}$ (SAID \& PIETRO, 2004), os quais apresentaram $\mathrm{pH}$ ótimo igual a 4,6. Albertson, Peters \& Grof (2001) isolaram diferentes isoformas de invertase de cana-deaçúcar e encontraram que a invertase ácida solúvel tem um pH ótimo de 4,5, sendo esta uma invertase ligada ao crescimento e diferenciação, enquanto que invertases encontradas na parede celular tem um pH ótimo entre 3,2 e 3,6. Já no citosol a invertase apresentou um $\mathrm{pH}$ de 7,3, caracterizando-se como neutra.

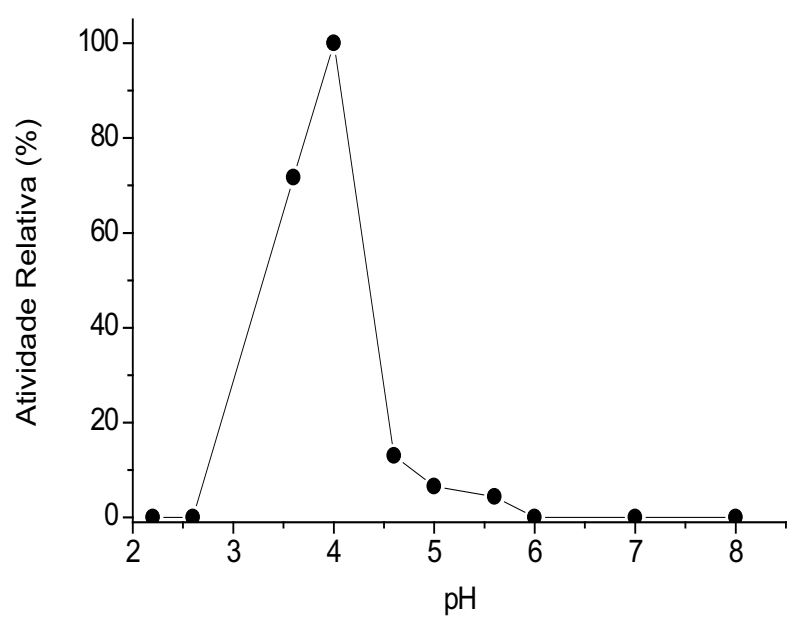

\section{Figura 4 - Influência do $\mathrm{pH}$ sobre a atividade} da invertase incubada a $60^{\circ} \mathrm{C}$

Outros pHs ótimos foram descritos como 3,85 para a invertase de Pycnoporus sanguineus (QUIROGA et al., 1995), 4,5 para a enzima produzida por células de bambu (Bambusa edulis) (LIU et al., 2006), 5,5 para a invertase produzida pela levedura Candida utilis (CHÁVEZ et al., 1997) e 6,0 e 5,5 para invertases da bactéria Zymomonas mobilis intracelular e extracelular, respectivamente.

HASHIZUME et al. (2003) observaram $\mathrm{pH}$ ótimo de 4,5 para uma invertase ácida purificada de pêra japonesa.

\subsection{EFEITO DE ÍONS, AGENTES QUELANTES E REDUTORES SOBRE A ATIVIDADE DA INVERTASE}

Para avaliar os requerimentos e resistência da invertase quanto a íons, agentes redutores e quelante, soluções de sais foram adicionadas ao meio de reação em concentração final de 1 e $5 \mathrm{mM}$; e solventes e detergentes a 1 e $5 \%$. Os resultados estão expressos na tabela 4. Muitas enzimas requerem íons metálicos como co-fatores para atividade catalítica. A invertase de $A$. casiellus não demonstrou necessidade de íons para a atividade catalítica, já que o agente quelante EDTA não provocou redução significativa na atividade basal da enzima.

Os íons $\mathrm{Cu}^{+}$e $\mathrm{Al}^{3+}$, na concentração de 5 $\mathrm{mM}$, foram os que mais ativaram a invertase, sendo este aumento de atividade invertásica em torno de 35,58 e 59,92\%, respectivamente. De acordo com Nguyen et al. (2005), a invertase de Aspergillus niger IMI303386 foi ativada por $\mathrm{Ba}^{+2}$, além de outros íons como $\mathrm{Mg}^{+2}, \mathrm{Ca}^{+2}$ e EDTA. Também a invertase de $A$. ochraceus foi ativada em $20 \%$ por $\mathrm{Ba}^{+2}$.

$\mathrm{Na}$ tabela 4 pode-se observar que as substâncias que mais inibiram a atividade invertásica deste fungo foram $\mathrm{NH}_{4}^{+}$com inibição de $11,26 \%$; $\mathrm{Na}^{+}$com $15 \%$ na concentração de $5 \mathrm{mM} ; \mathrm{Hg}^{2+}$ com $33 \%$ e os agentes redutores $\beta$-mercaptoetanol e DTT com inibição de $28,74 \%$ e $72,07 \%$, respectivamente. Os solventes acetona e etanol também provocaram a perda de atividade em torno de $30 \%$. Íons como o $\mathrm{Zn}^{+2}, \mathrm{Ag}^{+}, \mathrm{Ni}^{+2}$ e $\mathrm{Hg}^{+2}$ foram fortes inibidores da invertase de $A$. niger IMI303386 (NGUYEN et al., 2005), $\mathrm{Hg}^{+2}$ também foi encontrado como inibidor da invertase de A. ochraceus, sendo que a concentração de $10 \mathrm{mM}$ desta substância inibiu completamente a atividade invertásica (GUIMARĀES et al., 2007).

Comparando-se então, com estas referências, foi observado o comportamento oposto da invertase quanto à presença do $\mathrm{Zn}^{+2}$. Darren $\&$ Botha (1998) observaram a inibição completa de uma invertase básica com $\mathrm{Hg}^{2+}, \mathrm{Zn}^{+}$e $\mathrm{Ag}^{+}$.

A cisteína mostrou-se um importante ativador catalítico tendo um aumento de $243 \%$ na atividade da invertase. Este aumento significativo na atividade catalítica pela cisteína também foi observado por Liu et al. (2006), porém permanece a necessidade de estudos para melhor entendimento do fenômeno, já que não há uma explicação plausível na literatura. 
Tabela 4 - Efeito de íons (na forma de soluções salinas), solventes, agentes quelante e redutores sobre a atividade da invertase de Aspergillus casiellus

\begin{tabular}{lcc}
\hline \multirow{2}{*}{ Sais e outros agentes } & \multicolumn{2}{c}{ Atividade residual (\%) } \\
\cline { 2 - 3 } & $1 m M$ & $5 \mathrm{mM}$ \\
\hline Controle & 100 & 100 \\
$\mathrm{CuCl}$ & 122,69 & 135,58 \\
$\mathrm{KCl}$ & 99,98 & 94,97 \\
$\mathrm{HgCl}$ & 95,97 & 77,08 \\
$\mathrm{NaCl}$ & 91,62 & 85,26 \\
$\mathrm{NH}_{4} \mathrm{Cl}$ & 89,31 & 88,74 \\
$\mathrm{SnCl}_{2}$ & 99,47 & 74,87 \\
$\mathrm{BaCl}_{2} .2 \mathrm{H}_{2} \mathrm{O}$ & 120,51 & 134,44 \\
$\mathrm{CuSO}_{4}$ & 109,48 & 142,09 \\
$\mathrm{FeSO}_{4}$ & 102,27 & 130,37 \\
$\mathrm{Al}_{4}\left(\mathrm{SO}_{4}\right)_{3}$ & 146,23 & 159,92 \\
$\mathrm{ZnSO}_{4}$ & 101,12 & 118,04 \\
$\mathrm{MgSO}_{4}$ & 88,08 & 79,09 \\
Etanol & 97,20 & 71,86 \\
Acetona & 87,21 & 73,13 \\
$\mathrm{DTT}_{\mathrm{SDS}}$ & 81,70 & 27,93 \\
DMSO & 74,45 & 45,52 \\
$\mathrm{~B}_{-}$-mercaptoetanol & 97,12 & 57,55 \\
Tween 80 & 94,68 & 71,26 \\
Triton x 100 & 99,24 & 90,34 \\
EDTA $_{\text {Cisteína }}$ & 93,61 & 87,98 \\
\hline & 99,86 & 100,69 \\
& 130,02 & 342,97 \\
\hline
\end{tabular}

\subsection{ESPECIFICIDADE AO SUBSTRATO DA INVERTASE DE $A$. CASIELLUS}

A invertase de Aspergillus casiellus purificada foi incubada com diferentes substratos. Foi verificado que a enzima apresentou maior especificidade à sacarose $1 \mathrm{M}$ (Figura 5). As atividades enzimáticas para os demais substratos foram baixas quando comparadas à sacarose $1 \mathrm{M}$. A invertase não apresentou atividade quando incubada com pectina $1 \%$. A inulina também foi hidrolisada pela invertase de $A$. ochraceus obtida em meio Khanna suplementado com bagaço de cana de açúcar purificada por Guimarães et al. (2007), assim como pela invertase de $A$. casiellus. A especificidade ao amido foi verificada por Hashizume et al. (2003) e, como neste trabalho, sua enzima invertase foi pouco específica a este substrato.

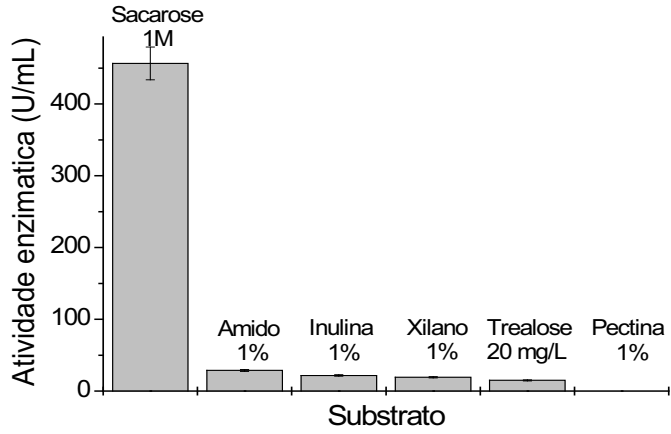

Figura 5 - Especificidade da invertase de $A$. casiellus a diferentes substratos

\section{CONCLUSÃO}

O resíduo de farelo de soja demonstrou ser um bom substrato indutor para utilização em fermentação em estado sólido por Aspergillus casiellus para produção de invertase e destaca-se o grande volume deste resíduo que é produzido na região.

Pode-se concluir neste trabalho também o êxito em recuperar a invertase através de choque térmico, uma alternativa nova e satisfatória que desperta mais interesse para novos estudos. Em relação às características da invertase recuperada, os valores de $\mathrm{pH}$ e temperatura ótimos, foram de 4,0 e $70^{\circ} \mathrm{C}$, respectivamente. Esta enzima demonstrou termoresistência em altas temperaturas de 60 a $70^{\circ} \mathrm{C}$ não atingindo o tempo de meia vida em $240 \mathrm{~min}$. E nas temperaturas de 75 a $80^{\circ} \mathrm{C}$ foram mantidas aproximadamente $40 \%$ da atividade residual após 4 horas de incubação. Fato que a torna muito interessante para processos industriais que acontecem em condições de temperatura elevada e pHs ácidos e apresentem variaçõos consideráveis que demandam enzimas resistentes e capazes de atuar em diferentes intervalos de temperatura. Por possuir características iguais ou melhores do que as de outras invertases encontradas na literatura, e algumas características próprias como, tempo de fermentação relativamente curto $(72 \mathrm{~h})$, alta produção enzimática, ser altamente termoresistente, a invertase produzida por Aspergillus casiellus tornase uma forte candidata à aplicação em processos industriais e biotecnológicos. 


\section{REFERÊNCIAS BIBLIOGRÁFICAS}

ALBERTSON, P.L., PETERS, K., GROF, C.P.L. An improved method for the measurementof cell wall invertase activity in sugarcane tissue. Journal of Plant Physiology, n.28, p.323-328, 2001.

ASHOKKUMAR, B., KAYALVIZHI, N. \& GUNASEKARAN, P. Optimization of media for $\beta$-fructofuranosidase production by Aspergillus niger in submerged and solid state fermentation. Process Biochmistry, n.37, p.331-338, 2001

BHATTI, H. N., RASHID, M.H., NAWAZ, R., ASGHER, M., PERVEN, R., JABBAR, A. Purification and characterization of a novel glucoamylase from Fusarium solani. Food Chemistry, v.103, p.338-343, 2007.

BRADFORD, M.M. A rapid and sensitive Method for the quantitation of microgram quantities of protein utilizing the principle of protein-dye binding. Analytical Biochemistry, v.72, p.248254, 1976.

BLUM, H., BEIER, H., GROS, H.J. Improved silver staining of plants proteins, RNA and DNA in polyacrilamides gels. Eletrophoresis, v.81, p.93-9, 1988.

CHÁVEZ, F.P.; RODRIGUEZ, L., DIAZ, J., DELGADO, J.M., CREMATA, J.A. Purification and characterization of invertase from Candida utilis: comparison with natural and recombinant yeast invertases. Journal of Biotechnology, v.53, n.1, p.67-74, 1997.

COELHO, G.D. Produção e caracterização do sistema xilanolítico excretado por Aspergillus giganteus. Rio Claro, 2002, 57p. Dissertação (Mestrado), Universidade Estadual Paulista "Julio de Mesquita Filho".

DARREN, J., BOTHA, F. Partial purification and characterization of sugarcane neutral invertase. Phytochemistry. v.49, n.3, p.651-655, 1998.

DAVIS, B.J. Disc eletrophoresis II - Method and application to human serum proteins. Ann. NY Aca. Sci., v.121, p.404-27, 1964.
DEL BIANCHI, V.L., MORAES, I.O., CAPALBO, D.M.F. Fermentação em estado sólido. In: LIMA, U.A. et al. Biotecnologia industrial: Engenharia bioquímica. $1^{a}$. Ed., v.3. São Paulo: Edgard Blücher, 2001, p.247-276.

GUIMARÃES, L. H. S., TERENZI, H.F., POLIZELI, M.L.T.M, JORGE, J.A. Production and characterization of a thermostable extracellular $\beta$-D-fructofuranosidase produced by Aspergillus ochraceus with agroindustrial residues as carbon sources. Enzyme and Microbial Technology. v.42, p. 52-57, 2007.

HASHIZUME, H., TANASE, K., SHIRATAKE, K, MORI, H., YAMAKI, S. Production and characterization of two soluble acid invertase isozymes from Japanese pear fruit. Phytochemistry. v.63, p.125-129, 2003.

HUSSAIN, A., RASHID, M., PERVEEN, R., ASHRAF, M. Purification, kinetic and thermodynamic characterization of soluble acid invertase from sugarcane. Plant Phys. et Bioch., in press, 2008.

LAEMMLI, U.K. Cleavage of structural proteins during the assembly of the head of bacteriophage T4. Nature, v.227, p.680-85, 1970.

L'HOCINE, L., WANG, Z., JIANG, B., XU, S. Purification and partial characterization of fructosyltransferase and invertase from Aspergillus niger AS0023. Journal of Biotechnology. v.81, p.73$84,2000$.

LIU, C.C., HUANG, L.C., CHANG, C.T., SUNG, H.Y. Purification and characterization of soluble invertases from suspension-cultured bamboo (Bambusa edulis) cells. Food Chemistry. v.96, p.621-631, 2006.

MILLER, G. L. Use of dinitrosalicylic acid reagent for determination of reducing sugar. Analitical Chemistry, v.31, p.426-489, 1959.

MORENO, S., SANCHEZ, Y., RODRIGUEZ, L. Purification and characterization of the invertase from Schizosaccharomyces pombe. Journal of Biochemistry. n.267, v.267, p.697-702, 1990. 
NGUYEN, Q.D., REZESSY-SZABO, J.M., BHAT, M.K., HOSCHLE, A. Purification and some properties of \%/fructofuranosidase from $A s-$ pergillus niger IMI303386. Process Biochemistry, v.40, p.2461-2466, 2005.

PERALTA, R.M. Procedimentos de isolamento e racionamento de proteínas. In: BRACHT, A. \& ISHII-IWAMOTO E. L. Métodos de laboratório em bioquímica. São Paulo: Manole, 2003.

QUIROGA, E.N., VATTUONE, M.A., SAMPIETRO, A.R. Purification and characterization of the invertase from Pycnoporus sanguineus. Biochimica et Biophysica Acta-Protein structure and molecular Enzymology, n.1251, p.75-80, 1995.

RUBIO, M.C., RUNCO, R., NAVARRO, A.R. Invertase from a strain of Rhodotorula glutinis. Phytochemstry, v.61, p.605-609, 2002.
SAID, S., PIETRO, R.C.L.R. Enzimas como agentes biotecnológicos. $1^{\text {a }}$. Ed.. Ribeirão Preto:Legis Summa, 2004

SOCCOL, C.R., VANDERBERGHE, L.P.S. Overview of applied solid-state fermentation in Brazil. Biochemical engineering Journal, n.13, p.205-218, 2003.

TANG, X., RUFFNER, H.P., SCHOLES, J.D., ROLFE, S.A. Purification and characterization of soluble invertases from leaves of Arabidopsis thaliana. Planta, v.198, p.17-23, 1996.

\section{AGRADECIMENTOS}

Os autores agradecem à Fundação Araucária pelo financiamento do projeto. 